\title{
Eflorescencias y costras sobre areniscas de Villamayor. Ensayos de laboratorio
}

\author{
F. MADRUGA \\ Euroconsult. Salamanca \\ J. SAAVEDRA \\ CSIC. Salamanca \\ M.T. MARTÍN PATINO \\ CSIC/UAM. Madrid \\ Fecha de recepción: 9-XII-93 \\ ESPAÑA

\section{RESUMEN} \\ Ensayos acelerados realizados en el laboratorio, permiten \\ estudiar el material cristalino depositado sobre la \\ superficie de areniscas cuando están en contacto con \\ disoluciones acuosas de diferente composición. \\ Probetas de areniscas de tres texturas diferentes se \\ colocan sobre bandejas que contienen las disoluciones \\ acuosas, de tal forma que una de las superficies esté en \\ contacto con el líquido. \\ Sobre las superficies opuestas se establece una corriente \\ de aire que acelere la absorción capilar del liquido.

\section{SUMMARY} \\ Accelerated tests carried out in the laboratory allow us to \\ study the crystalline material settled over the surface of \\ the sandstones when in contact with watery solutions of \\ different compositions. \\ Sandstone specimens of three different textures were \\ placed on trays containing watery solutions, putting one \\ surface in contact with the liquid. In order to accelarate \\ the capillary absorption, a flow of air was established \\ over the opposite surfaces. The humidity and dryness \\ cycles were repeated 45 times.
} Ciclos de humedad y secado se repiten 45 veces.

Las sales cristalizadas se identifican por difracción de rayos-X, SEM y microanálisis quimico por energía dispersiva de rayos- $X$. Los resultados son los siguientes; yeso, hexahidrita, picromerita, natrón y arcanita cuando se trata de disoluciones salinas; trona, aftitalita y presencia de yeso cuando la disolución es de cemento; yeso y syngenita en el ensayo con disolución de guano. Estas sales son análogas a las encontradas en las piedras superficialmente deterioradas de las Catedrales de

Salamanca.
The crystallized salts were identified by $X$-ray diffraction, $S E M$ and chemical microanalysis by $X$-rays dispersive energy. The following results were obtained: gypsum, hexahydrite, picromerite, natrone, arcanite in saline solutions; trone, aftitalite, and presence of gypsym in cement solutions; gypsum and syngenite in the guano solution test. These salts are analogous to those found in the superficially damaged stones of the Cathedral of Salamanca.

\section{INTRODUCCIÓN}

La cristalización de sales solubles en el interior o sobre la superficie de las piedras es un aspecto importante del deterioro en numerosos edificios y monumentos. Estas cristalizaciones en forma de eflorescencias y costras surgen de las disoluciones acuosas cuando las condiciones de humedad relativa y temperatura crítica son las adecuadas para su formación. El crecimiento en el interior de la piedra causa la disrupción del material.
La naturaleza, origen, hábitoy condiciones de formación de estas sales, en piedras de distintas construcciones, han sido ya estudiadas por otros investigadores. Entre los que podrían citarse: Arnold (1973), Charola y Lewín (1979), Arnold(1982), Zehnder y Arnold (1984), Arnold y Kueing, Arnold y Zehnder (1985), Binda y Baronio (1987), Arnold y Zehnder (1989). 
La porosidad alta de la piedra favorece el proceso de cristalización; éste es el caso de las areniscas de Villamayor con porosidades entre 20 y $30 \%$.

Nosotros estudiamos las consecuencias producidas sobre areniscas después de haber estado en contacto con disoluciones acuosas que transportan diferentes sales solubles. Se simulan aquellas disoluciones que pueden afectar con más frecuencia a la piedra de los edificios.

Los ensayos permiten la observación del material depositado, la identificación de su naturaleza y formas cristalinas.

\section{ENSAYOS EXPERIMENTALES}

La experiencia se realizó con areniscas procedentes de tres bloques sacados de la cantera de Villamayor, en los que el aspecto textural de la piedra era diferente en cada uno de ellos: fino, menos fino (denominado medio) y grueso. De cada uno de estos bloques se cortaron tres probetas en forma de cubo, de $4 \mathrm{~cm}$ de arista.

En la situación real de un edificio las disoluciones acuosas que afectan principalmente a la piedra son; a) las aguas subterráneas enriquecidas en nitratos y cloruros; b) aguas que han estado en contacto con otros materiales de la construcción, como es el caso del cemento; y c) aguas que arrastran detritos animales depositados en techumbres y muros. Con este criterio se prepararon tres disoluciones: a) Disolución salina neutra de $\mathrm{Cl}-$, NO3- e OH-, de Na+, $\mathrm{Mg}++, \mathrm{Ca}++, \mathrm{K}+$ y NH4+ en agua. b) Cemento en agua. c) Agua que ha estado durante algún tiempo en contacto con guano.

Las probetas se colocaron sobre bandejas conteniendo cada una de las disoluciones, de tal forma que una de las caras del cubo estuviera en contacto con el líquido. La experiencia se realiza dentro de un túnel donde se establece corriente de aire durante cinco horas diarias, tratando de favorecer la evaporación en superficie y que ésta acelere la absorción capilar. La temperatura fué aproximadamente de $20^{\circ} \mathrm{C}$. El ensayo se basa en el realizado por Alcalde (1988). Cada ciclo de humedad y secado dura ocho días (cinco días en contacto con el líquido y tres días de secado a temperatura ambiente), repitiéndose 45 veces. Durante este tiempose observaron formaciones de costras y eflorescencias sobre las superficies que estaban al aire (figura 1). Otra experiencia semejante se realizó con agua desionizada, no apreciando ningún cambio visible en la piedra.

La estructura, morfología y composición química de las sales cristalizadas se identificaron por difracción de rayos-X, microscopía electrónica de barrido y el microanálisis químico por energía dispersiva de rayos$\mathrm{X}$.
Otra experienciallevada a cabo consistió en determinar los componentes químicos aportados por la piedra al estar en contacto con agua. Cien gramos de piedra triturada se trataron con $500 \mathrm{ml}$ de agua desionizada durante 7, 14, 28 y 125 días, al final de cada uno de estos periodos el agua filtrada se analizó por medio de espectrofotometría de absorción atómica. La experiencia se repitió con cada una de las areniscas: gruesa, media y fina.

\section{RESULTADOS}

Los resultados de los análisis químicos del agua, después de haber estado en contacto con la piedra durante el tiempo indicado, se muetran en los gráficos de la figura 2. Se aprecia una relación entre la textura de la piedra y la concentración de cationes aportados al agua: siempre mayor en las finas y menor en las gruesas. Respecto al tiempo de tratamiento, las concentraciones $\mathrm{de} \mathrm{K}+\mathrm{y} \mathrm{Na}+$ tienen variaciones insignificantes, mientras las de $\mathrm{Ca}++$ y $\mathrm{Mg}++$ crecen hasta duplicarse después de 100 días, independientemente de la textura que tenga la piedra.

Terminados los ciclos de tratamiento con las distintas disoluciones, las sales cristalizadas sobre las superficies de las probetas son identificadas por medio de los difractogramas de la figura 3. Estas sales son: yeso ( $\left.\mathrm{SO}_{4} \mathrm{Ca} .2 \mathrm{H}_{2} \mathrm{O}\right)$, hexahidrita $\left(\mathrm{SO}_{4} \mathrm{Mg} \cdot 6 \mathrm{H}_{2} \mathrm{O}\right)$, picromerita $\left(\left(\mathrm{SO}_{4}\right) \mathrm{K}_{2} \mathrm{Mg} \cdot 6 \mathrm{H}_{2} \mathrm{O}\right)$, natron $\left(\mathrm{CO}_{3} \mathrm{Na}_{2} \cdot 10 \mathrm{H}_{2} \mathrm{O}\right)$ y arcanita $\left(\mathrm{SO}_{4} \mathrm{~K}_{2}\right)$ cuando la disolución es salina; trona $\left(\left(\mathrm{CO}_{3}\right)_{2} \mathrm{Na}_{3} \mathrm{H} .2 \mathrm{H}_{2} \mathrm{O}\right)$ como componente mayoritario, aftitalita $\left(\left(\mathrm{SO}_{4}\right) \mathrm{K}_{3} \mathrm{Na}\right)$ y presencia de yeso en el ensayo con disolución de cemento; yeso y singenita $\left(\left(\mathrm{SO}_{4}\right)_{2} \mathrm{~K}_{3} \mathrm{Ca} . \mathrm{H}_{2} \mathrm{O}\right)$ en el ensayo con disolución de guano. El microanálisis de elementos químicos por energía dispersiva de rayos- $\mathrm{X}$, además de confirmar estas sales, da la presencia de otros cristales que contienen $\mathrm{P}$ y $\mathrm{Mg}$ cuando la disolución es de guano. Se supone en cantidades insuficientes para ser detectadas por difractometría de rayos- $\mathrm{X}$.

Las imágenes de SEM en las figuras 4, 5 y 6 muestran las morfologías de los cristales.

La naturaleza de las sales cristalizadas sobre piedras de distintas texturas es la misma, no obstante se aprecian ligeras diferencias en el grado de cristalinidady tamaño de éstas. Un estudio detallado de las causas que llevan a tal efecto aún no se ha realizado, habría que tener en cuenta las diferencias en la concentración de elementos que aportan al agua según la textura, como se ha comprobado en los análisis químicos presentados anteriormente, y también las diferencias que, relacionadas con la textura, tiene la estructura interna de las piedras. 
Estas sales formadas en ensayos de laboratorio son análogas a las que han cristalizado sobre las piedras, superficialmente deterioradas, de las Catedrales de Salamanca, estudiadas por Martin Patino y col. (1992).

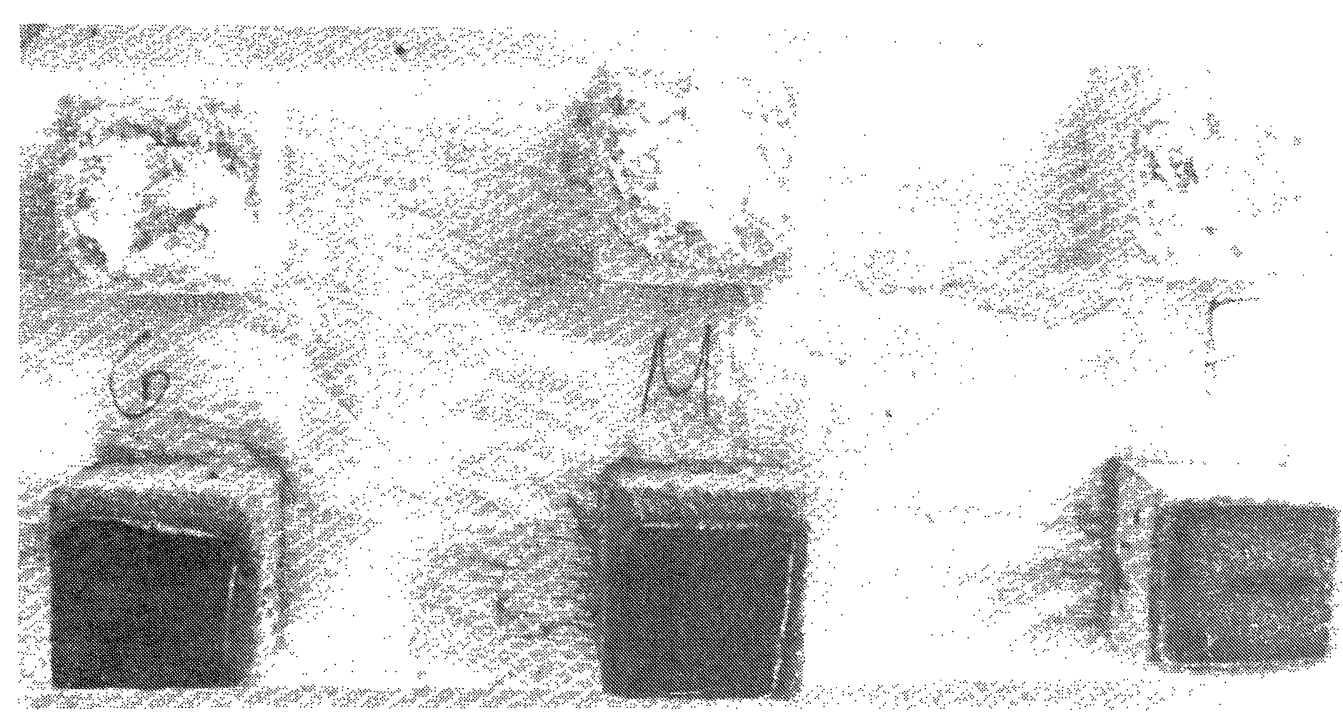

Fig.1.- Cubos de arenisca de $4 \mathrm{~cm}$ de arista después de los ensayos de humedad-secado con distintas disoluciones. Cristalizaciones de sales sobre la superficie.
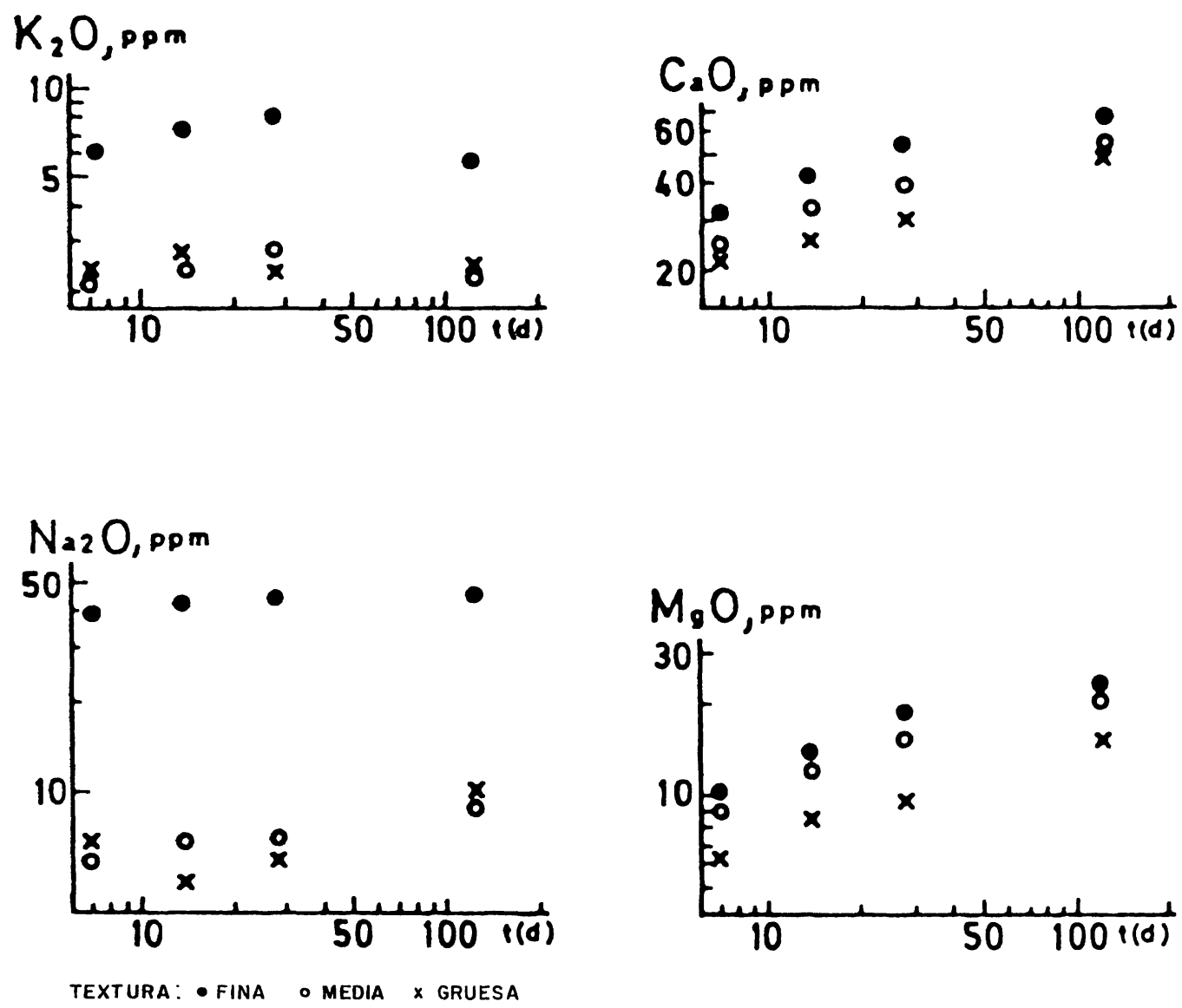

Fig.2.-Representación gráfica de los resultados obtenidos en el análisis químico de agua después de haber estado en contacto con areniscas de tres texturas diferentes. 
1 YESO

2 HEXAHYDRITA

3 PICROMERITA

4 NATRON

5 ARCANITA
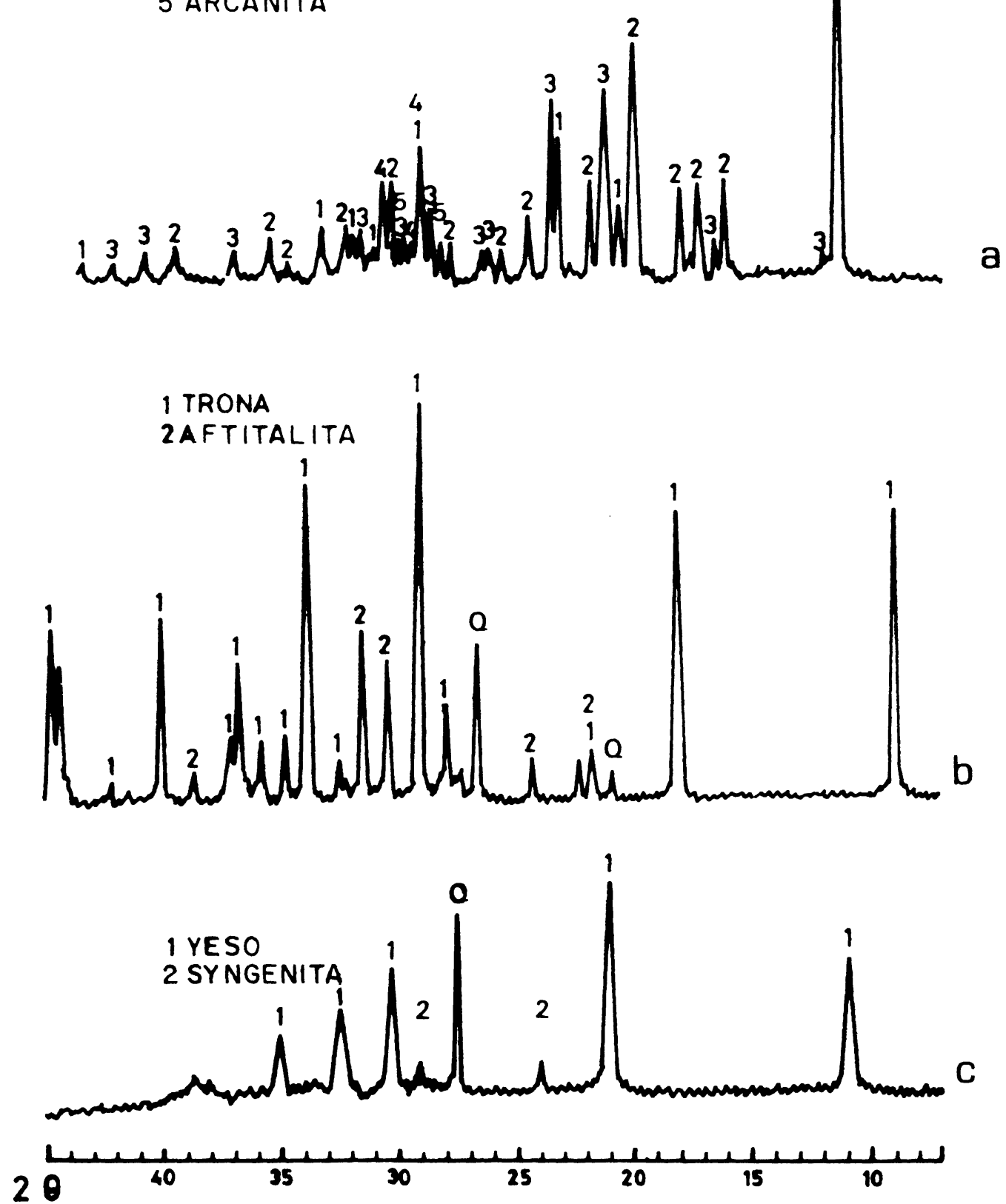

Fig.3.- Difractogramas de sales después del tratamiento con: a) disolución salina; b) disolución de cemento; c) disolución de guano. 


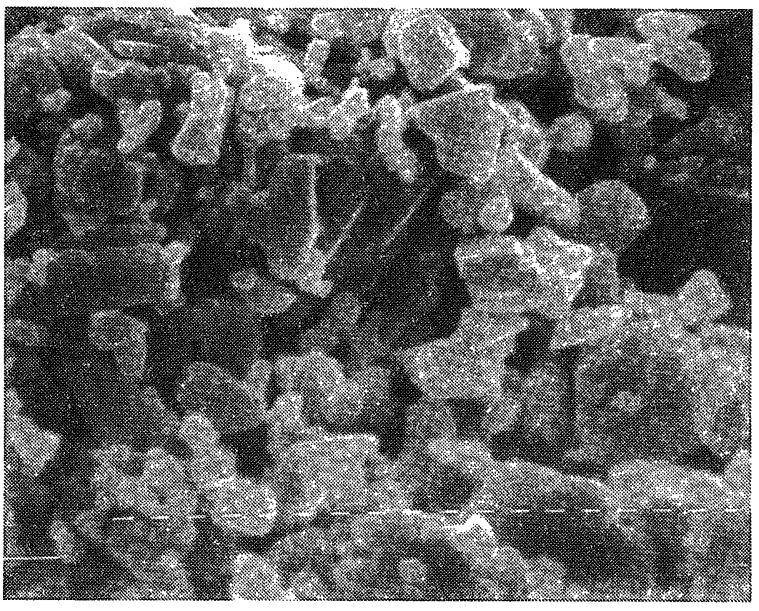

a

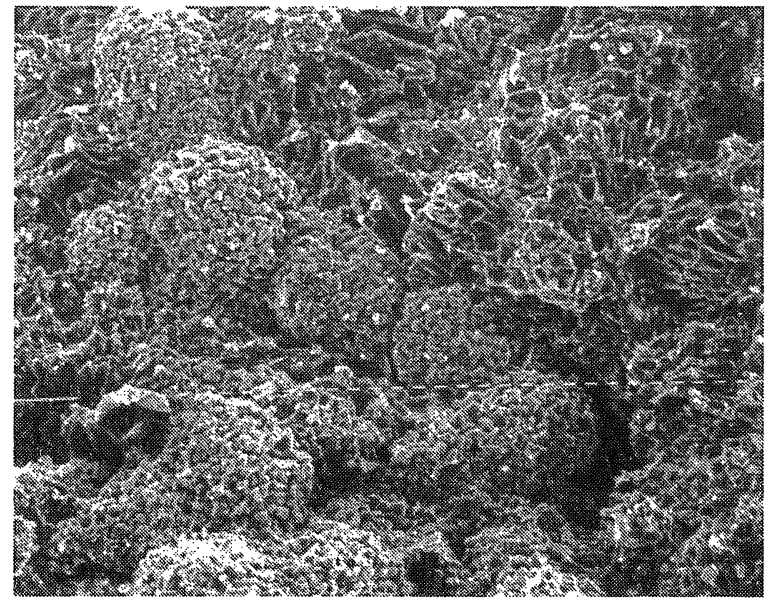

c

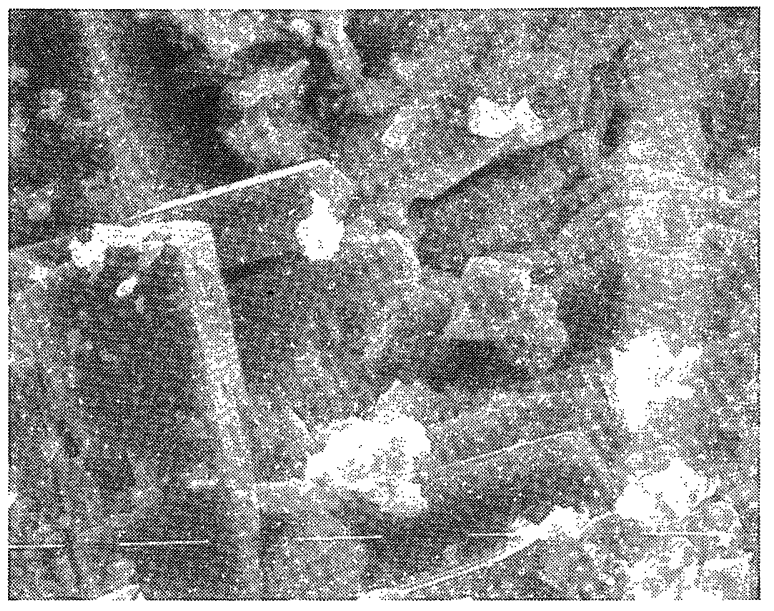

b

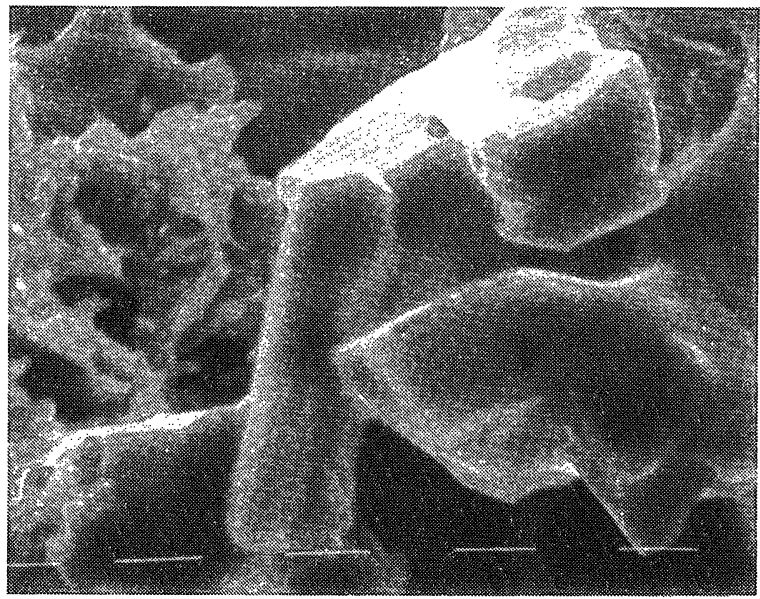

d

Fig.4.- Imágenes de SEM. Cristalizaciones sobre arenisca en contacto con una disolución salina: a) yeso y hexahidrita, barra $=10 \mu \mathrm{m} ; \mathrm{b})$ yeso, barra $=1 \mu \mathrm{m} ; \mathrm{c}$ ) trona, barra $=10 \mu \mathrm{m} ; \mathrm{d})$ arcanita, barra $=10 \mu \mathrm{m}$.

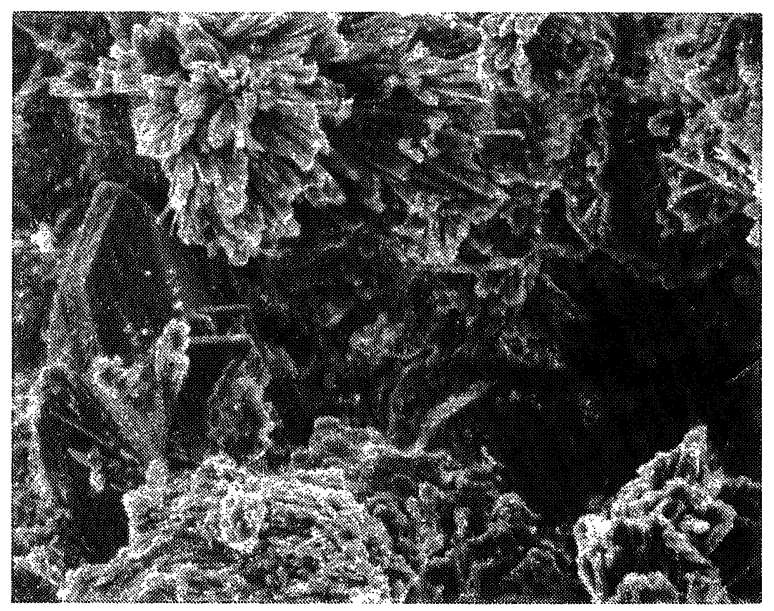

a

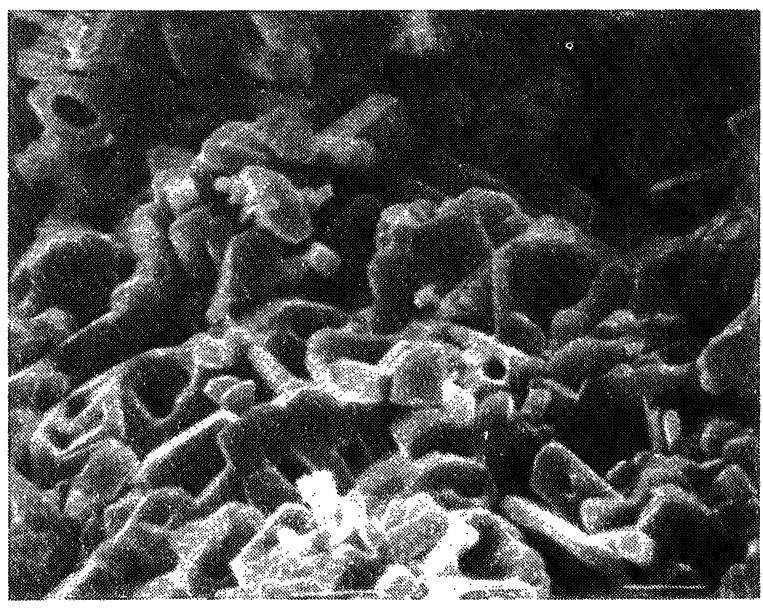

b

Fig.5.- Imágenes de SEM. Cristalizaciones sobre arenisca en contacto con disolución de cemento: a) trona y un cristal de yeso en la parte izquierda de la imagen; b) aftitalita y trona, barra $=10 \mu \mathrm{m}$. 


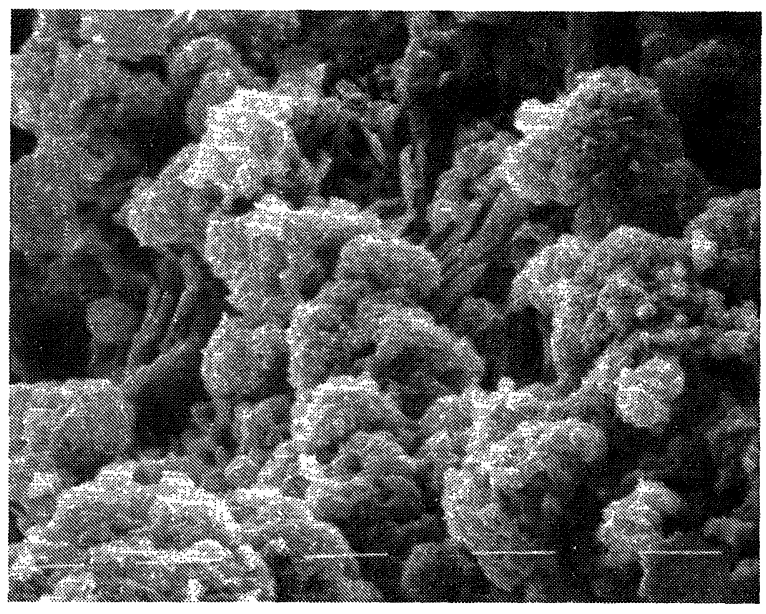

a

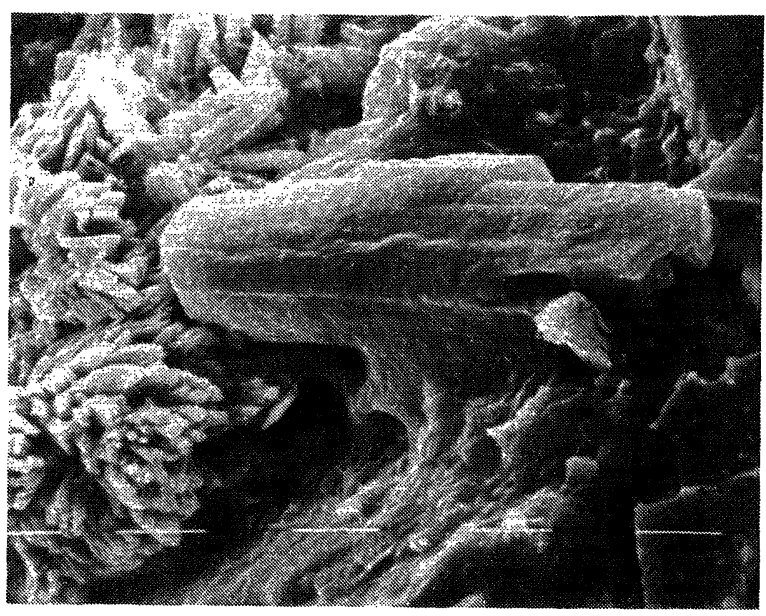

b

Fig.6.- Imágenes de SEM. Cristalizaciones sobre arenisca en contacto con disolución de guano: a) yeso, barra=10 $\mu \mathrm{m} ; \mathrm{b})$ syngenita y en el centro un cristal de fosfato de magnesio, barra $=10 \mu \mathrm{m}$.

\section{BIBLIOGRAFÍA}

(1) ALCALDE, M., (1988), Sintomatología de alteraciones de las catedrales de Sevilla, Cádiz y Almería. Tesis Doctoral, Universidad de Sevilla.

(2) ARNOLD, A.,(1973), Behaviour of soluble salts in stone deterioration. 2nd. International Symposium on the Deterioration of Building stones, Athens, 27-36.

(3) ARNOLD, A., (1982), Rising damp and saline minerals. 4th Int. Cong. Deterior. Preserv. Stone Objects, Louisville, 11-28.

(4) ARNOLD, A. and KUENG, A., (1985), Cristallization and Habits of Salt Efflorescences on Walls. Part I, Methods of Investigation and Habits. Vth International Congress on Deterioration and Conservation of Stone. Lausanne, 255-268.

(5) ARNOLD, A. and ZEHNDER, K., (1985), Cristallization and Habits of Salt Efflorescences on Walls. Part II, Conditions of Cristallization. Vth International Congress on Deterioration and Conservation of Stone, Lausanne, 269-277.

(6) ARNOLD, A.and ZEHNDER, K., (1989), Soluble salts and stone decay. The Conservation of Monuments in the Mediterranean Basin. Proceed. of the 1st. Symp., Bari, 31-58.

(7) BINDA, L. and BARONIO, G., (1987), Mechanisms of masonry decay due to salt cristallization. Durability of Building Materials. Vol. 4, n. 3, 227-240.

(8) CHAROLA, A.E. and LEWIN, S.Z., (1979), Efflorescences on Building Stones - SEM in the Characterization and Elucidation of the Mechanisms of Formation. Scanning Electron Micriscopy, SEM Inc., AMF O'Hare, 379-386.

(9) MARTIN PATINO, M.T., MADRUGA, F. and SAAVEDRA, J., (1992), Characterization of the Sandstone of the Salamanca Cathedrals. Forms of Weathering. 7th International Congress on Deterioration and Conservation of Stone. Lisbon, 315-324.

(10) ZEHNDER, K. and ARNOLD, A., (1984), Stone damage due to formate salts. Studies in Conservation, 29, 32-34. 